\title{
Trypanosoma cruzi: Correlations of Biological Aspects of the Life Cycle in Mice and Triatomines
}

\author{
Valdirene S Lima, Regina HR Mangia*, João C Carreira, \\ Renato S Marchevsky**, Ana M Jansen/ ${ }^{+}$
}

\begin{abstract}
Departamento de Protozoologia *Departamento de Bioquímica e Biologia Molecular **Departamento de Neurovirulência, Instituto Oswaldo Cruz, Av. Brasil 4365, 21045-900 Rio de Janeiro, Brasil
\end{abstract}

The infection pattern in Swiss mice and Triatomine bugs (Rhodnius neglectus) of eleven clones and the original stock of a Trypanosoma cruzi isolate, derived from a naturally infected Didelphis marsupialis, were biochemically and biologically characterized. The clones and the original isolate were in the same zymodeme (Z1) except that two clones were found to be in zymodeme 2 when tested with G6PDH. Although infective, neither the original isolate nor the clones were highly virulent for the mice and lesions were only observed in mice infected with the original stock and one of the clones (F8). All clones and the original isolate infected bugs well while only the original isolate and clones E2 and F3 yielded high metacyclogenesis rates. An observed correlation between absence of lesions in the mammal host and high metacyclogenesis rates in the invertebrate host suggest a evolutionary trade off i.e. a fitness increase in one trait which is accompanied by a fitness reduction in a different one. Our results suggest that in a species as heterogeneous as T. cruzi, a cooperation effect among the subpopulations should be considered.

Key words: Trypanosoma cruzi - Rhodnius prolixus - histopathology - life cycle - clone-trade-off

The phenomena of virulence and specificity of parasites have been increasingly examined from an evolutional and ecological point of view (Ferreira da Silva 1972, Humphery-Smith 1989, Adamson \& Caira 1994, Lenski \& May 1994, Ebert \& Herre 1996). Despite the many conflicting conceptions, it is believed that virulence can be maintained as a fitness trait of the parasite (Ebert \& Herre 1996).

One of the most puzzling aspects of Trypanosoma cruzi (Kinetoplastida, Trypanosomatidae) is the extreme heterogeneity of this species. The so called subpopulations of the parasite vary in relation to their virulence and tissular tropism (Bice \& Zeledon 1970, Andrade 1974, Andrade et al. 1983, 1985) morphology (Brener \& Chiari 1963) isoenzymatic profiles (Toyé 1974, Miles et al. 1977, Dvorak et al. 1980), schyzodeme patterns (Morel et al. 1980, Gonçalves et al. 1984), lectin agglutination patterns (Schottelius 1982), doubling time and growth kinetics in axenic media (Dvorak et al. 1980, Lauria-Pires et al. 1992, 1996).

Financial support: Papes-CNPq.

${ }^{+}$Corresponding author. Fax: +55-21-598.4323. E-mail: Jansen@gene.dbbm.fiocruz.br

Received 26 June 1998

Accepted 3 February 1999
The attempts that have been made in order to correlate these parameters with epidemiology and/or the infection pattern of man and animals have led to conflicting results although some common features could be established including the zymodeme profiles and the domestic or sylvatic transmission cycle (Miles 1983).

In addition, correlation between the growth kinetics and the course of the experimental infection in mice as well as between different cariotypes with distinct zymodeme profiles have been described (Dvorak et al. 1980, Andrade et al. 1983, Heriksson et al. 1993).

On the other hand, no relationship could be observed among zymodeme, schyzodeme, lectin agglutination pattern, doubling time and growth curves of 27 clones and the original isolate of $T$. cruzi drived from a naturally infected marsupial (Didelphis marsupialis) by Mangia et al. (1995). The significant differences in the virulence and in tissular tropism patterns observed in the infections by $T$. cruzi are frequently accepted as an intrinsic trait of a given subpopulation of the parasite (Bice \& Zeledon 1970, Andrade 1974, Andrade et al. 1983, 1985). Other authors have proposed that the differences in the clinical aspects observed in Chagas disease are due to differences in the human (host) populations.

We decided to follow up the experimental infection of triatomid bugs and swiss mice with 11 clones and the original isolate from a $T$. cruzi 
stock derived from a naturally infected opossum. Our main objective was to identify possible correlations among the pattern of the experimental infection of the vertebrate and invertebrate host with different clones and the original isolate of a sylvatic strain of $T$. cruzi, in order to better understand the mechanisms related to the virulence of this parasite.

\section{MATERIALS AND METHODS}

Parasites - The isolate (G-327) was obtained through hemoculture in NNN with a LIT overlay of a naturally infected opossum ( $D$. marsupialis) captured in Jaguanum Island, State of Rio de Janeiro.

The parasite cloning was performed with the EPICS 751 Flow Cytometer (Coulter Eletronic, Hialeah, FL) at the Institute Oswaldo Cruz, Fiocruz, Rio de Janeiro, Brazil. The clones were obtained and maintained by passage in LIT medium.

Characterization of the zymodeme profiles Five enzymes, GPI (E.C. 5.3.1.9), IDH (E.C.1.1.1. 103), G6PHD (E.C.1.1.1. 49), ME (E.C. 1.1.1.40) and PGM (E.C. 2.7.5.1) were tested by agarose gel electrophoresis according to Momem and Salles (1985).

Samples of the original isolate as well as from the 11 clones were frozen in liquid nitrogen.

Triatomine bugs - The studied bugs were 3rd and 4th instar nymphs of $R$. neglectus kindly supplied by the National and International reference Laboratory for Taxonomy in Triatomids of the Entomology Department, Institute Oswaldo Cruz. Since we could not find any triatomid bugs in Jaguanum Island, where the naturally infected opossum was captured we chose $R$. neglectus, because this species is a good host for sylvatic strains of $T$. cruzi as we already observed.

Mice - All experimental infections were performed in Swiss male outbred mice weighing 20 g. The inocula were adjusted to yield $10^{5}$ metacyclic trypomastigotes harvested from LIT medium and were inoculated intraperitoneally.

Experimental infection of triatomids - Approximately 30 specimens of $R$. neglectus were infected with the 11 clones and the original isolate (G-327) respectively.

The bugs were infected through an artificial membrane (Garcia et al. 1975) and the infecting meal was prepared with log phase epimastigotes obtained from axenic culture medium (LIT) added to rabbit red blood cells previously washed in $0.15 \mathrm{M}$ PBS. The infecting meal contained $10^{6}$ parasites $/ \mathrm{ml}$.

Each batch of insect was weighted before and after the infecting meal in order to evaluate the average dose of ingested parasites. All non engorged bugs were eliminated.

A clean blood meal was offered 30 days later and again, the non engorged insects were eliminated.

Sixty days after the infecting meal, batches of 15 bugs were anesthetized with chloroform, dissected and each whole digestive tract was collected, ground in a known volume of $0.15 \mathrm{M}$ PBS for differential counting in Neubauer chamber.

Experimental infection of mice - Five of the eleven clones (E2, F3, E11, B3, F8) and the original isolate (G-327) were inoculated as already described in six mice each.

From the second day of infection onward, the parasitemia was followed through fresh blood smears, every other day.

An indirect imunofluorescence assay (IFA) was performed weekly with each animal. An antimouse IgG FITC labeled (SIGMA ${ }^{\hat{a}}$ ) was used.

The animals were monitored during a period of 60 days after which titration of antibodies, hemocultures and necropsy were performed.

The following viscera were collected in Millonig for histopathology: esophagus, stomach, small and large intestine, kidneys, bladder, heart, skeletal muscles, liver, spleen and lungs.

Mice immunization - Epimastigotes in $\log$ phase of the clones F3 and F8 were disrupted in a sonicator. After centrifugation, the protein content of the supernatant was measured spectrophotometrically at $260 \mathrm{~nm}$ and $280 \mathrm{~nm}$ (Milton Roy Co.) and six mice per clone were injected subcutaneously twice with $15 \mathrm{mg}$ of the protein with an interval of two weeks between injections.

Serum was obtained weekly from individual mice to determine the specific IgG titer.

\section{RESULTS}

Two distinct zymodeme patterns were observed: the isosenzymatic profiles of five enzymes GPI, IHD, G6PHD, ME and PGM corresponded to $\mathrm{Z} 1$, for G-327 and for nine of the 11 clones. The two remaining clones displayed a profile that corresponded to Z2 zymodeme (Miles et al. 1977) when tested for G6PDH and Z1 for the other four enzymes tested.

Experimental infection of triatomid bugs - The results of the experimental infection of $R$. neglectus with 11 clones and the original isolate are summarized in the Table. All clones and G-327 efficiently colonized the digestive tract of $R$. neglectus.

Concerning the clones, the final number of flagellates in the digestive tract of the insects ranged between $2 \times 10^{4}$ and $9 \times 10^{4}$ independent of the number of ingested parasites that in two cases (clones B3 and F3) was almost 100 fold higher. This was not the case for the bugs infected with 
G-327 which presented a significantly higher number of parasites in the gut, in comparison to the number of ingested flagellates (Table).

Metacyclogenesis rates differed significantly among clones and the original isolate. The majority of clones displayed a very low metacyclogenesis rate with the exception of the clones E2 and F3 (Table).

Follow up of the experimental infection of Swiss mice - All infected mice displayed a subpatent but stable infection with scarce positive fresh blood examinations. The survival rate of the mice was $100 \%$ and the hemocultures done at the necropsy were positive.

Mice infected with clone F8 and G-327 presented the most intense lesions: moderate lymphomacrophagic infiltrates were found in skeletal muscle fibers (Fig. 1). Scarce destruction of muscle fibers and perivascular infiltrates could also be observed (Figs 2, 3, 4). The lesions observed in the mice were comparable with those seen by Carreira et al. (1995) in naturally infected opossums D. marsupialis.

Infection with clones E11 and B3 resulted in insignificant infiltrates composed of few lymphocytes and macrophages only in the skeletal muscular tissue. Mice infected with clones E2 and F3 displayed no lesions at all. The hearts of all mice were free from lesions.

Serological monitoring - The kinetics of the humoral immune response varied according to inoculated clone. Mice infected with G-327 reached the highest serological titer $(1: 320)$ at the

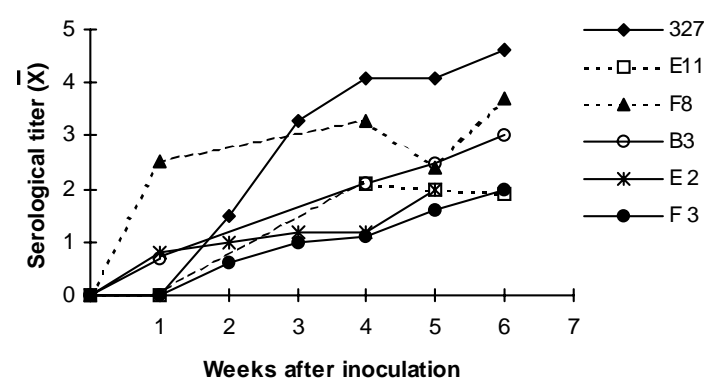

Fig. 1: average levels of IgG of six mice inoculated with a Trypanosoma cruzi strain isolated from a Didelphis marsupialis (G-327 - -) and five derived clones (E11 - $\square$-; F8 - $\mathbf{\Delta}$ - ; B3 -TM_ ; E2 -*- and F3 - - ). The immunoglobulins were detected by an indirect immunofluorescence test. The curves were plotted as $\log 2$ of the dilution titers.

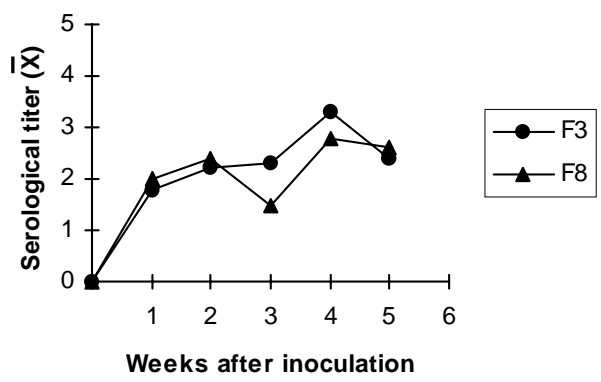

Fig. 2: average levels of IgG of mice immunized with two clones (F3 - - and F8 - $\boldsymbol{\Delta}$-) derived from a Didelphis marsupialis isolate (G-327). The immunoglobulins were detected by an indirect immunofluorescence test. The curves were plotted as $\log 2$ of the dilution titers.

TABLE

Experimental infection of Rhodnius neglectus with Trypanosoma cruzi (G-327 strain) and 11 derived clones: average number of epimastigotes ingested, the number of parasites in the digestive tract after 60 days, metacyclogenesis rates $(\%)$ and positivity $(\%)$

\begin{tabular}{lcccr}
\hline Clones & $\begin{array}{c}\text { Average no. } \\
\text { of ingested } \\
\text { epimastigotes }\end{array}$ & $\begin{array}{c}\text { No. of parasites }(\overline{\mathrm{X}}) \text { in } \\
\text { the digestive tract of } \\
\text { Rodnius neglectus } \\
\text { after } 60 \text { days }\end{array}$ & $\begin{array}{c}\% \\
\text { metacyclogenesis } \\
\text { rates }\end{array}$ & $\begin{array}{c}\% \\
\text { positivity }\end{array}$ \\
\hline $\mathrm{B}_{3}$ & $8 \times 10^{6}$ & $7.7 \times 10^{4}$ & 2.2 & 100 \\
$\mathrm{C}_{6}$ & $2.5 \times 10^{5}$ & $6 \times 10^{4}$ & 9 & 100 \\
$\mathrm{C}_{9}$ & $5 \times 10^{5}$ & $6.1 \times 10^{4}$ & 2.4 & 77 \\
$\mathrm{E}_{2}$ & $6 \times 10^{4}$ & $7.2 \times 10^{4}$ & 70 & 76 \\
$\mathrm{E}_{11}$ & $6 \times 10^{4}$ & $1.7 \times 10^{4}$ & 11 & 70 \\
$\mathrm{~F}_{2}$ & $7.5 \times 10^{4}$ & $3.4 \times 10^{4}$ & 1.8 & 75 \\
$\mathrm{~F}_{3}$ & $7.6 \times 10^{6}$ & $5 \times 10^{4}$ & 57 & 72 \\
$\mathrm{~F}_{8}$ & $5.1 \times 10^{4}$ & $4 \times 10^{4}$ & 22 & 91 \\
$\mathrm{G}_{5}$ & $8.5 \times 10^{4}$ & $2 \times 10^{4}$ & 0 & 77 \\
$\mathrm{G}_{10}$ & $7.6 \times 10^{4}$ & $8.9 \times 10^{4}$ & 6.4 & 78 \\
$\mathrm{H}_{8}$ & $6 \times 10^{5}$ & $4.7 \times 10^{4}$ & 3.4 & 81 \\
$\mathrm{G}-327$ & $9 \times 10^{4}$ & $4 \times 10^{5}$ & 68 & 100 \\
\hline
\end{tabular}




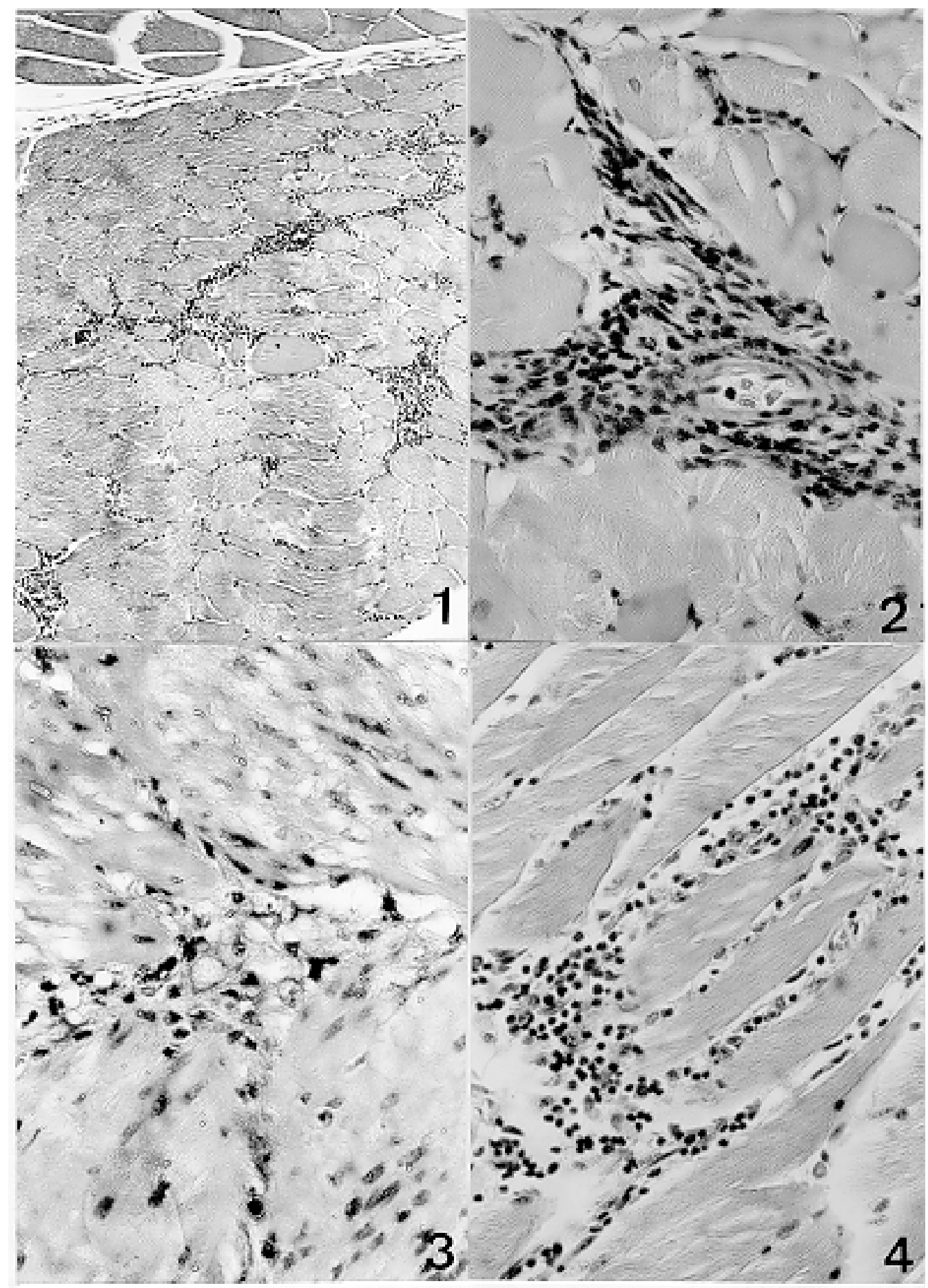

Fig. 3: histopathological findings of mice inoculated with the clone F8: diffuse inflammatory reaction in skeletal muscle fibers (1), with perivascular reaction (2), scarse muscle fiber destruction (3 and 4). 
week sixth after inoculation. The lowest titers were observed in the animals inoculated with clones E2 and F3: around 1:40 in the fifth and sixth week postinoculation respectively (Fig. 1).

In order to evaluate if the low levels of specific antibodies were due to a unique trait characteristic of the parasite or to the consequence of some peculiarity related to the interaction of mice with that given clone, we immunized six mice with clones F3 (responsible for low antibody titers in infected mice) and B3 (responsible for high antibody titers in infected mice). The second hypothesis was confirmed since the immunized animals reached similar specific IgG levels (Fig 2).

\section{DISCUSSION}

Concerning the experimental infection of $R$. neglectus, our results confirm our previous experience and are in accordance with the findings of Moreira and Perlowagora-Szumlewics (1997) which demonstrated that $T$. cruzi colonizes well the digestive tract of this triatomine species.

The low metacyclogenesis rates could not be correlated with zymodeme since this was the same for G-327 which presented high metacyclogenesis rate, as well as for the clones with low metacyclogenesis rate.

Most clones presented a very low metacyclogenesis rate $(0-10 \%)$; only two clones (E2 and F3) reached comparable levels of differentiation to that observed with the original isolate (Table). Besides admitting that the clones with low metacyclogenesis rate are not significantly representative of the original isolate, we should not rule out the hypothesis of some "cooperation effect" that resulted from assemblage of the clones in the original isolate that would result in the high differentiation rates observed in the original isolate. Such an effect could explain the maintenance in nature of the clones that do not differentiate as well as the extensively studied clone CL-14 that does not infect mice (Lima et al. 1991). In this context, social organization and cooperation as important factors in the trypanosomatid evolution was suggested by Vickerman (1994).

G-327 and the derived clones were infective but not remarkably virulent for the Swiss mice in contrast to experimentally infected young laboratory born opossum which display high parasitemias that reach $10^{5}$ parasites/ml even with a five fold lower inoculum (data not shown).

The low virulence of a sylvatic isolate of $T$. cruzi for Swiss mice is not always the norm. In previous experiments we observed up to $100 \%$ mortality in Swiss mice inoculated with isolates derived from naturally infected Philander opossum (Marsupialia, Didelphidae) and Leonto- pithecus rosalia (Primata, Callithricidae), (Lisboa et al. 1996, Pinho et al. 1996) .

Correlation between the humoral immune response and the intensity of the histopathological lesions could be observed. Infections with E2 and F3 clones resulted in no lesions at all and very low antibody titers (1:40). High antibody titers were observed in the animals inoculated with the clones F8, E11, B3 and with G-327 although the tissular lesions were significantly more intense in the animals inoculated with the original isolate and the F8 clone. The high antibody titers observed in the animals immunized with the F3 clone indicated that the low titers in the infected animals were probably due to a particularity of this host parasite model and not to the unresponsiveness of the mice.

Correlation could also be observed between the metacyclogenesis rate and the severity of the tissular lesions: the experimental infection with clone F8 which displayed a low metacyclogenesis rate in insects, produced more severe lesions in the mice, in contrast to the clones E2 and F3 that presented high metacyclogenesis rates and insignificant tissular lesions in the infected mice. High metacyclogenesis rates result in higher ability of the clone to disperse to the mammal host in which, inversely, the minor lesions suggest a lower capacity to colonize. The opposite condition is represented by the clone F8. This correlation could suggest a evolutionary trade off i.e. a fitness increase in one trait which is accompanied by a fitness reduction in a different trait (Stearns 1992, Ebert \& Herre 1996).

Our data confirm that infection and/or disease is the result of many factors related to the host and to the parasite at a given moment and highlight a still poorly known aspect - this refers to the consequences of the interaction of different subpopulation of a parasite in a given environment of the host. This aspect should be taken into account principally if we consider a species as heterogeneous as $T$. cruzi.

\section{ACKNOWLEDGEMENTS}

To Alvaro Bertho for operation of flow cytometer and Alcidineia Ivo for technical assistance.

\section{REFERENCES}

Adamson ML, Caira JN 1994. Evolutionary factors influencing the nature of parasite specificity. Parasitology (Suppl.) 109: 85-95.

Andrade SG 1974. Caracterização de cepas de Trypanosoma cruzi isoladas no recôncavo Baiano. Rev Pat Trop 3: 65-121.

Andrade V, Barral-Netto M, Andrade SG, Magalhães JB 1985. Aspectos imunológicos da infecção de seis linhagens isogênicas de camundongos por três 
diferentes cepas de Trypanosoma cruzi. Mem Inst Oswaldo Cruz 80: 203-211.

Andrade V, Brodskyn C, Andrade SG 1983. Correlation between isoenzyme patterns and biological behaviour of different strains of Trypanosoma cruzi. Trans R Soc Trop Med Hyg 77: 796-799.

Bice DE, Zeledon R 1970. Comparison of infectivity of strains of Trypanosoma cruzi (Chagas, 1909). J Parasitol 56: 663-670.

Brener Z, Chiari E 1963. Variações morfológicas em diferentes amostras de Trypanosoma cruzi. Rev Inst Med Trop São Paulo 5: 220-224.

Carreira JCA, Jansen AM, Lenzi HL, Deane MP 1996. Histopathological study of Didelphis marsupialis natural and experimental infections by Trypanosoma cruzi. Mem Inst Oswaldo Cruz 91: 609-618.

Dvorak JA, Hartman DL, Miles MA 1980. Trypanosoma cruzi: correlationa of growth kinetics to zymodeme type in clones derived from various sources. $J$ Protozool 27: 472-474

Ebert D, Herre EA 1996. The evolution of parasitic diseases. Parsitol Today 12: 96-101.

Ferreira da Silva LF 1972. O fenômeno parasitismo. Rev Soc Bras Med VII: 261-277.

Garcia ES, Macarini JD, Garcia MCN, Ubatuba FB 1975. Alimentação de Rhodnius prolixus no laboratório. An Acad Bras Ciências 47: 537-545.

Gonçalves AM, Nehme NS, Morel CM 1984. Trypanosomatid characterization by schizodeme analysis, p. 95-109. In CM Morel, Genes and Antigenes of Parasites a Laboratory Manual, 2nd ed., Fundação Oswaldo Cruz, Rio de Janeiro.

Henriksson J, Pettersson U, Solari A 1993. Trypanosoma cruzi: correlation between karytype variability and isoenzyme classification. Exp Parasitol 77: 334-348.

Humphery-Smith I 1989. The evolution of phylogenetic specificity among parasitic organisms. Parasitol Today 12: 385-387.

Lauria-Pires L, Bogliolo AR, Santana JM, Teixeira ARL 1992. Characterization of stocks and clones of $T$. cruzi obtained from patients with cardiac and digestive forms of Chagas' disease. Mem Inst Oswaldo Cruz (Suppl. II) 87: 103.

Lauria-Pires L, Bogliolo AR, Santana JM, Teixeira ARL 1996. Diversity of Trypanosoma cruzi stocks and clones derived from Chagas' disease patients. Exp Parasitol 82: 182-190.

Lenski RE, May RM 1994. The evolution of virulence in parasites and pathogens: reconciliation between two competing hypothesis. J Theor Biol 169: 253-265.

Lima MT, Jansen AM, Rondinelli E, Gatass CR 1991. Trypanosoma cruzi: properties of a clone isolated from CL strain. Parasitol Res 77: 79-81.

Lisboa CV, Dietz J, Baker A, Mangia RHR, MenezesTrajano V, Ivo A, Jansen AM 1996. Transmission of Trypanosoma cruzi among Golden Lion Tamarin (Leontopithecus rosalia) in Poço das Antas Biological Reserve, Rio de Janeiro, Brasil. Mem Inst Oswaldo Cruz 91 (Suppl.): 279.

Mangia RHR 1995. Trypanosoma cruzi: Caracterização Biológica e Bioquímica de Clones de um Mesmo Isolado Obtido de Didelphis marsupialis Naturalmente Infectado, Msc Thesis, Instituto Oswaldo Cruz, Fiocruz, Brasil, 50 pp.

Miles MA 1983. The epidemiology of South American trypanosomiasis, biochemical and immunological approaches and their relevance to control. Trans $R$ Soc Trop Med Hyg 78: 526-535.

Miles MA, Toye PJ, Oswald SC, Godfrey DG 1977.The identification by isoenzyme patterns of two distinct strain-groups of Trypanosoma cruzi circulating. Trans R Soc Trop Med Hyg 71: 217-225.

Momem H, Salles CA 1985. Enzime markers for Vibrio cholerae: identification of classical EL Tor and environmental strains. Trans $R$ Soc Trop Med Hyg 79: 773-776.

Moreira CJC, Perlowagora-Szumlewics A !997. Attempts to improve xenodiagnosis: comparative test of sensibility using Rhodnius neglectus, Panstrongilus megistus, Triatoma vitticeps and Triatoma infestans in endemic areas of Brazil. Mem Inst Oswaldo Cruz 92: 91-96.

Morel C, Chiari E, Camargo E P, Mattei DM, Romanha AJ, Simpson L 1980. Strains and clones of T. cruzi can be characterized by pattern of restriction endonuclease products of Kinetoplast DNA minicircle. Proc Nat Acad Sci USA 77: 6810-6814.

Pinho AP, Mangia RH, Nehme N, Morel CM, Cupolillo E, Jansen AM 1996. The complexity of the circulation of Trypanosoma cruzi in the natural environment: Biological and biochemical characterization of marsupial and Rhodnius prolixus isolates. Mem Inst Oswaldo Cruz 91 (Suppl.): 220.

Schottelius J 1982. The identification by lectins of two strain groups of T. cruzi. Z Parasitenk 68: 147-154.

Stearns SC 1992. The Evolution of Life Histories, Oxford University Press, $42 \mathrm{pp}$.

Toyé PJ 1974. Isoenzyme variation in isolates of Trypanosoma cruzi . Trans R Soc Trop Med Hyg 68: 147158.

Vickerman K 1994. The evolutionary expansion of the trypanosomatid flagellates. Int J Parasitol 24: 1317 1331. 